\title{
HOSPITAL ENERGY ANALYSIS TOOLKIT (HEAT): USER MANUAL
}

\section{Stephen F. Weber Barbara C. Lippiatt}

\author{
U.S. DEPARTMENT OF COMMERCE \\ National Instltute of Standarids \\ and Tochnology \\ Center for Computing and Applled \\ Mathematlcs \\ Applled Economics Group \\ Galthersburg, MD 20899 \\ Sponsored by \\ U.S. DEPARTMENT OF HEALTH AND HUMAN \\ SERVICES \\ Public Health Service \\ Health Resources and Services \\ Adminlstration \\ Bureau of Health Resources Development
}

U.S. DEPARTMENT OF COMMERCE Robert A. Mosbacher, Secretary NATIONAL INSTTIUTE OF STANDARDS AND TECHNOLOGY

John W. Lyone, Director

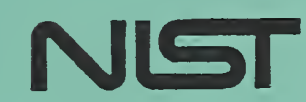





\section{HOSPITAL ENERGY ANALYSIS TOOLKIT (HEAT): USER MANUAL}

\section{Stephen F. Weber Barbara C. Lippiatt}

\author{
U.S. DEPARTMENT OF COMMERCE \\ Natlonal Institute of Standards \\ and Technology \\ Center for Computing and Applled \\ Mathematles \\ Applled Economles Group \\ Galthersburg, MD 20899
}

\section{Sponsored by} U.S. DEPARTMENT OF HEALTH AND HUMAN SERVICES

Publlc Health Service

Health Resources and Servlces Adminlstration

Bureau of Health Resources Development

September 1990

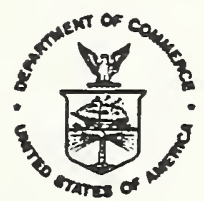

U.S. DEPARTMENT OF COMMERCE Robert A. Mosbacher, Secretary MATIONAL INSTITUTE OF STANDARDS AND TECHNOLOQY

John W. Lyons, Drrector 


\section{ABSTRACT}

The Hospital Energy Analysis Toolkit [HEAT] is a menu-driven microcomputer software program designed to help facility managers of existing hospitals evaluate the cost effectiveness of specific Energy Saving Methods (ESMs). The program estimates the energy savings and cost effectiveness of specific ESMs in a user-defined hospital environment. Hospitals are defined in terms of an unlimited number of actual functional space zones, each modeled after one of 21 prototype zones. For each defined zone, the user specifies the floor area, and for some zones the user specifies the types of heating and cooling systems, the percentage of space being actively used, and the window orientation. The user also defines an Energy Saving Plan by specifying the current and planned status of each energy parameter applicable to the particular zone. HEAT then computes and reports the energy and economic savings resulting from the Plan. A benchmarking function lets users compare current energy use of the entire hospital with national norms to see whether further analysis is warranted. HEAT offers easy-to-use menus and function keys, on-line help screens, and data validation.

Key Words: Cost effectiveness; decision support software; economic evaluation; energy conservation; hospitals; life-cycle cost analysis; microcomputer software 


\section{ACKNOWLEDGMENTS}

The authors wish to thank several colleagues for their collaborative contributions to this project. Stephen Petersen of NIST provided many insights on economic modeling of energy use in buildings. James Fireovid of W. S. Fleming and Associates, Inc. conducted the energy modeling of hospital space zones using ASEAM, A Simplified Energy Analysis Model, the microcomputer software program he developed. Dr. James Filliben of NIST provided expertise on statistical techniques for estimating interactive effects of energy saving methods. He also modified DATAPLOT, his interactive language for data analysis and graphics, to facilitate our analysis.

We are grateful to the Public Health Service (PHS) for sponsoring this research. The project monitors from the PHS Bureau of Health Resources Development provided ideas and guidance helpful in selecting the approach taken: Walter Collins, George Boysen, Richard Olmer, Pernell Crockett, and Richard Laeng.

We appreciate the helpful comments and suggestions we received from the hospital facility managers who served as Beta testers and from the NIST reviewers:

Stephen Petersen, Dr. James Hill, and George Walton. 
HEAT runs on an MS-DOStm microcomputer with at least 512 kilobytes of RAM and a hard disk drive. Before you can run HEAT, you must install it on a hard disk.

To install HEAT on a hard disk (for example on drive C):

1. Type C: and press ENTER to go to the hard drive on which HEAT is to be installed.

2. Insert diskette into drive $A$.

3. Type A:INSTALL and press ENTER. All the HEAT program and data files will be extracted and copied to a directory called \HEAT on drive C.

To run HEAT after installation on a hard disk (for example drive C):

1. Type $C$ : and press ENTER to make the hard disk the current drive.

2. Type CD $\backslash$ HEAT and press ENTER to go to the HEAT directory.

3. Type HEAT and press ENTER to start the program.

[For monochrome graphic systems like the Compaqtm Portable II or III, type HEAT $M$ and press ENTER.]

To quit HEAT and return to DOS:

1. Return to the HEAT Menu with the Escape key and press Esc again.

NOTE: Because HEAT needs several files open at all times, you may have to change the "FILES=" statement in the CONFIG.SYS file located in the root of your hard disk. If an error message with the words "open error" appears at the top of the screen, you need to increase the value in the "FILES=" statement to 15 or greater. For example, if your CONFIG.SYS file has no "FILES=" statement or the CONFIG.SYS file is missing altogether, a message like "proc HOSP line 17, open error hospital.MEM(4)" will appear when you select the Hospital Data option of the HEAT Menu. Refer to your MS-DOS ${ }^{t m}$ manual for more information on the FILES configuration statement. 
TABLE OF CONTENTS

ABSTRACT . . . . . . . . . . . . . . . . . . . . . . . . . . . $1 i$

ACKNOWLEDGMENTS . . . . . . . . . . . . . . . . . . . . . . . . . iii

HOW TO INSTALL AND RUN HEAT . . . . . . . . . . . . . . . . . . . . . . . . iv

TABLE OF CONTENTS . . . . . . . . . . . . . . . . . . . . . . . . . . . . . . . . . v

LIST OF EXHIBITS . . . . . . . . . . . . . . . . . . . . . . . . . . . . . . . . vi

1. INTRODUCTION AND OVERVIEW . . . . . . . . . . . . . . . . . . . . . . . . . 1

2. HOSPITAL DATA . . . . . . . . . . . . . . . . . . . . . . . . . . . 3

3. ZONE \& ENERGY PLAN DATA . . . . . . . . . . . . . . . . . . . . . . . . . . . . . 6

4. ENERGY USE BENCHMARK . . . . . . . . . . . . . . . . . . . . . . . . . . 11

5. RESULTS . . . . . . . . . . . . . . . . . . . . . . . . . . . . . . . . 13 
LIST OF EXIIBITS

Exhibit 1. HEAT Menu

Exhibit 2. Help Screen Explaining the HEAT Menu . . . . . . . . . . . . . . 2

Exhibit 3. Entering Hospital-Wide Data . . . . . . . . . . . . . . . . . . 3

Exhibit 4. Entering Fuel Prices and System Efficiencies . . . . . . . . . . 4

Exhibit 5. List of Energy Zone Prototypes . . . . . . . . . . . . . . . . . 6

Exhibit 6. Zone Prototypes and Available Configuration Options . . . . . . 7

Exhibit 7. Entering Energy Saving Plan for Patient Rooms Zone . . . . . . 8

Exhibit 8. Energy and Economic Results for Patient Rooms Zone . . . . . . . 9

Exhibit 9. ZONE DESCRIPTIONS with Patient Room Energy Plan Results . . . 10

Exhibit 10. Benchmarking Your Hospital's Energy Use . . . . . . . . . . . . 11

Exhibit 11. Viewing Energy and Economic Results by Zone . . . . . . . . . . 13 


\section{INTRODUCTION AND OVERVIEW}

The Hospital Energy Analysis Toolkit [HEAT] is a menu-driven microcomputer software program to assist facility managers of existing hospitals in evaluating the cost effectiveness of specific Energy Saving Methods (ESMs). The program estimates the energy savings and cost effectiveness of specific ESMs in a userdefined hospital environment. HEAT offers three analytical tools: (1) a benchmarking tool for hospital energy use; (2) an initial screening tool for ESMs; and (3) a tool to confirm the cost effectiveness of ESMs.

Benchmarking shows whether the current overall energy use of your hospital is in line with national averages for hospitals of similar configuration and size. The benchmarking results suggest how significant the energy saving opportunities are likely to be in your hospital. Even if your hospital uses less energy than the national average, however, some ESMs may still be cost effective, especially if fuel prices are relatively high in your area.

The screening tool lets you analyze specific ESMs using "best guess" preliminary cost estimates to identify the most promising ESMs for which bids should be sought. Finally, after the bids have been received, replace estimated with actual costs to confirm expected savings.

Once the program is started, the HEAT Menu appears with four options corresponding to four major steps in hospital energy analysis (Exhibit 1).

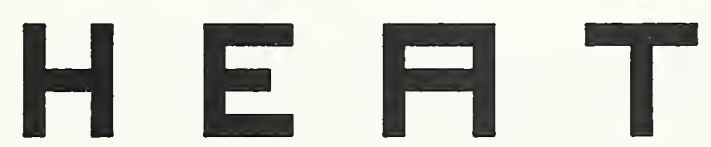

Hospital Energy Analysis Toolkit

Hospital Data

Zone \& Energy Plan Data

Energy Use Benchmark

Results

Use $\uparrow \downarrow$ to select and press $\downarrow$

F1 for Help Esc to Quit

Exhibit 1. HEAT Menu 
The first step is to describe the hospital in terms of its location and fuel types and prices. The second step is to divide the hospital into space zones by selecting any combination of 21 possible energy zone prototypes. Then you may go directly to the third step -- compute the Energy Use Benchmark which compares actual energy use with national average consumption. If actual energy use exceeds national average consumption or fuel prices are particularly high in your area, then further analysis with HEAT is probably worthwhile. Return to step two and enter detailed Energy Saving Plans for each zone. For each Energy Saving Plan, HEAT estimates the energy savings and displays the economic results. Proceed to step four to review from a single table the energy and economic results of the Energy Saving Plans for every zone.

Press F1 for a summary of these major steps (Exhibit 2). Throughout HEAT press F1 to see help screens that explain the current procedures.

Hospital Data

\section{Main Modules of HEAT}

Specify the hospital location [ZIP code] and name, the number of years and first year in the analysis study period, the discount rate, and electricity price. Record the types of heating and cooling fuels, the fuel prices, and the average seasonal efficiencies of the systems.

\section{Zone \& Energy Plan Data}

Describe details of your hospital by selecting any combination of the 21 possible energy zone prototypes. Enter the floor area for each zone and the type of heating/cooling system for most zones. For a few zone types you must also enter the percentage of area that is used and the main direction the windows face. Once all zones are defined, you may compute the Energy Use Benchmark or enter Energy Saving Plans by zone.

Energy Use Benchmark

Compare actual energy use with national average consumption by entering the monthly fuel consumption for each fuel type used. The Benchmark is meaningful only AFTER ALL hospital zones are defined since it is based on the floor area of each zone.

Overall Results

Display summary and detailed savings and costs for all hospital zones.

Exhibit 2. Help Screen Explaining the HEAT Menu 


\section{HOSPITAL DATA}

At the HEAT menu, select the module Hospital Data by moving the highlighted bar to this first option and pressing $\leftarrow$. A data entry screen appears (Exhibit 3).

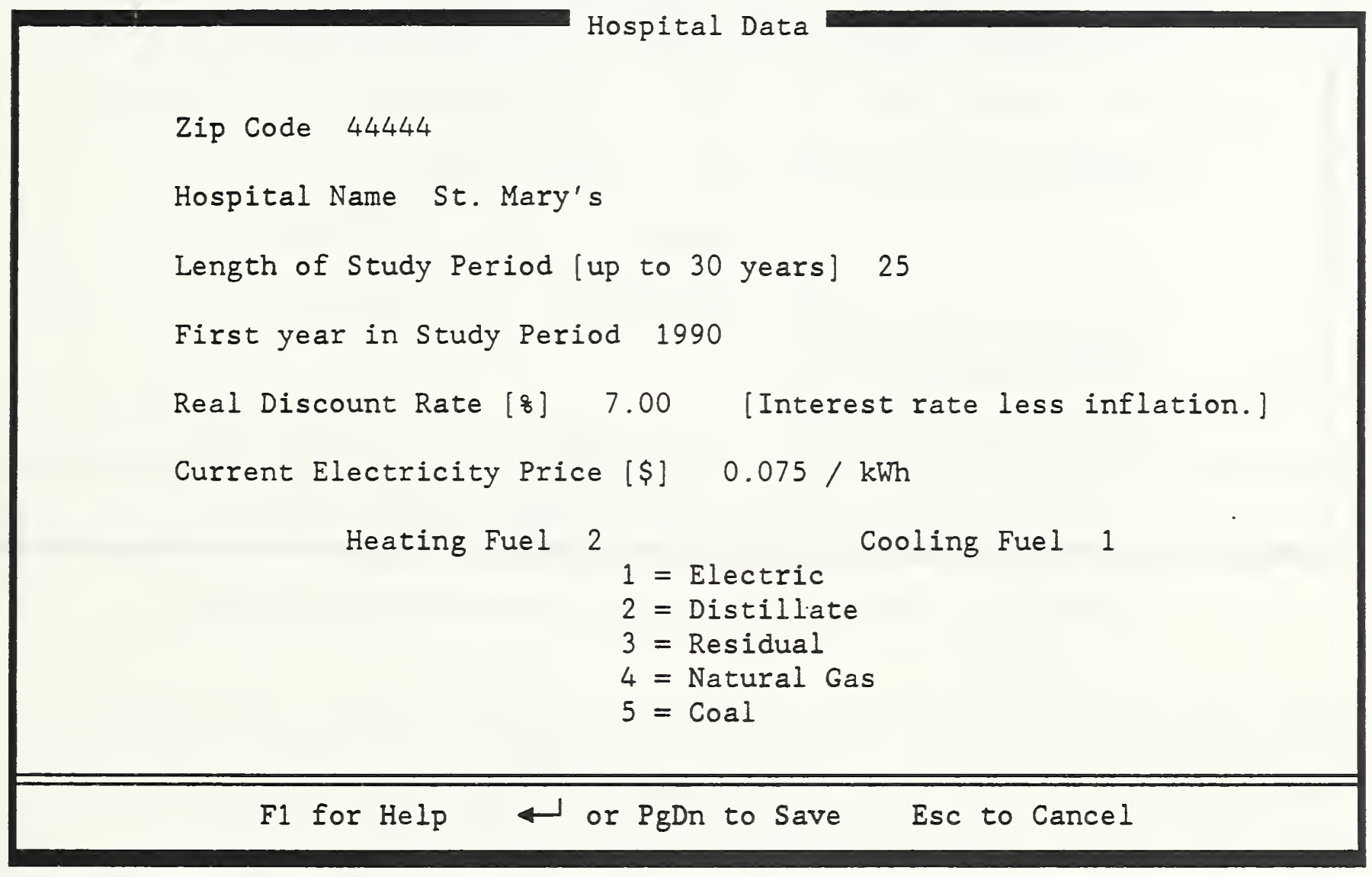

Exhibit 3. Entering Hospital-Wide Data

Enter the ZIP code where the hospital is located and its name. HEAT uses the first 3 digits of the ZIP to select the heating and cooling data files most closely resembling the energy needs of your location. There are six data files, each representing one city within the contiguous United States. The cities were selected as prototypical of a broad range of weather conditions Your ZIP code is also used to identify your region for U.S. Department of $E n$ y (DoE) energy price projections. Once you enter your ZIP code, HEAT identifics the heating and cooling data files it will use and your DoE Region (Exhibit 4). 


$\begin{array}{lllrl} & \text { DoE Energy Price Region: } 2 & \text { City Used for } 44444 \\ \text { Zip Code } 44444 & \text { Heating Degree Days: } 6600 & \text { CHICAGO } \\ & \text { Cooling Degree Hours: } 800 & \text { CHICAGO }\end{array}$

Hospital Name St. Mary's

Length of Study Period [up to 30 years] 25

First year in Study Period 1990

Real Discount Rate [\%] 7.00 [Interest rate less inflation.]

Current Electricity Price [\$] $0.075 / \mathrm{kWh}$

Heating Cooling

Fuel Distillate Electric

Seasonal Efficiency [\%] $65 \quad 225$

[With Distribution Loss]

Current Unit Price [\$] $0.642 /$ gal $0.075 / \mathrm{kWh}$

F1 for Help $\leftrightarrow$ or PgDn to Save Esc to Cancel

Exhibit 4. Entering Fuel Prices and System Efficiencies

Enter the Length and First Year of the analysis Study Period. The Length of Study Period is the longest time any of the Energy Saving Methods [ESM] are expected to be in force. Next enter the before-tax Real Discount Rate, which is the interest rate expected to be paid to finance the ESMs less your estimate of inflation. Thus, if your before-tax interest rate is 118 and inflation is about 4.5\%, your Real Discount Rate is about 6.5\%. Note that HEAT does not take into account any taxation effects of either the costs or energy savings of ESMs. ${ }^{1}$

Next enter your electricity price and types of heating and cooling fuels. For Electricity Price enter the cost avoided from saving $1 \mathrm{kWh}$ of lighting. Five types of fuels for heating and cooling are listed, each assigned a number code. These fuels are the only ones for which regional DoE energy price projections are available. Record the types of fuels the hospital uses for heating and cooling by entering the number code for each fuel. Distillate fuel oil includes No. 1 and 2 grade oils. Residual fuel oil includes No. 4, 5, and 6 grade oils.

${ }^{1}$ Taxation effects should be ignored when analyzing non-profit hospitals. For software that does account for taxes, see the National Bureau of standards Life-Cycle Cost (NBSLCC) microcomputer program, documented in Chapter 6 of Rosalie T. Ruegg and Stephen R. Petersen, Comprehensive Guide for Least-Cost Energy Decisions (Washington, DC: U. S. Government Printing Office, 1987). 
Once you've identified the hospital's heating and cooling fuels, the lower part of the screen will ask for fuel prices and effective seasonal efficiencies of the heating and cooling systems (Exhibit 4). The effective seasonal efficiency estimate should include both energy conversion and distribution losses and is defined here as the percentage ratio of satisfied energy load to purchased energy, averaged over the heating or cooling seasons. Distribution losses may be significant if ducts are routed through unconditioned spaces. 0 il and gas heating effective seasonal efficiency estimates vary from 30-90\%. Electric resistance heating efficiencies vary from 50-90\%. Effective cooling efficiency (equivalent to 100 times the Coefficient of Performance or C.O.P. less distribution losses) varies from 100 to $300 \%$. 


\section{ZONE \& ENERGY PLAN DATA}

Once the hospital-wide data is recorded, the HEAT menu reappears. Now select the module Zone \& Energy Plan Data. Divide the hospital into space zones, with each zone matching as closely as possible one of the 21 energy zone prototypes that are displayed when you press F4 (Exhibit 5). Press $\uparrow$ and $\downarrow$ to scroll through this screen. You may select the same prototype for more than one of the hospital's space zones. For example, the hospital may have two wings of patient rooms that you want to analyze separately, either because their orientation or HVAC system is different or because you want to study different Energy Saving Plans for each wing. After you select the zone prototype to represent a particular space, you may edit the name of the zone. For example, if you are modeling to wings of patient rooms differently, you may name them "Patient Rooms: West" and "Patient Rooms: East." However you edit a zone name, the analysis will always be based on the prototype zone you originally selected. Note that you may not need to use all 21 prototypes to describe your particular hospital.

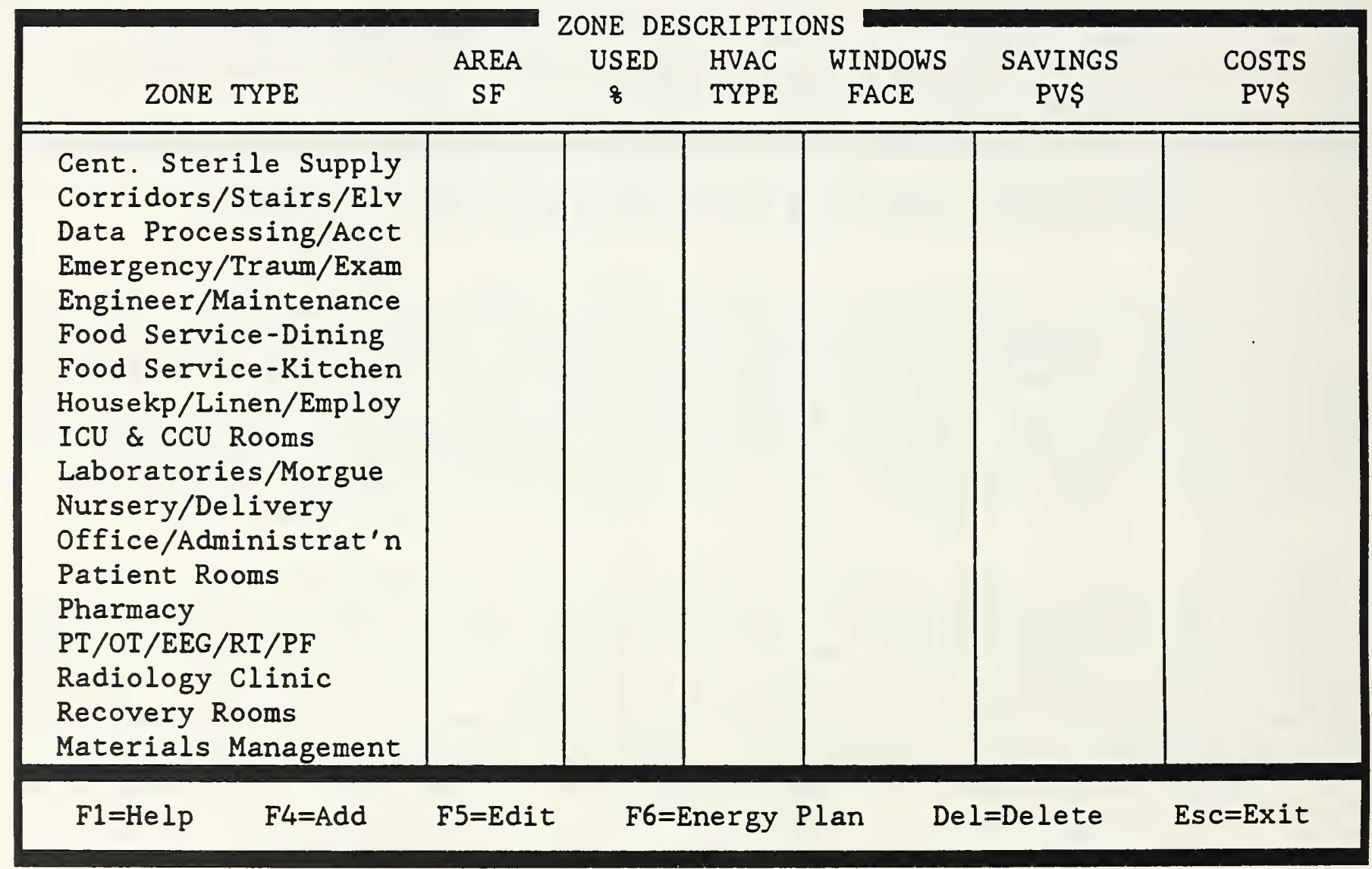

Exhibit 5. List of Energy Zone Prototypes 
For each hospital zone you add, enter the floor area. If prompted, also select the type of heating/cooling system (HVAC) most closely resembling the system in the zone being modeled. You will be prompted to select the HVAC type only if HEAT has available more than one type for that zone prototype. For several zone prototypes you must also enter the percentage of area that is used (i.e., cannot be temporarily closed off) and the primary direction the windows face. The percentage area and window orientation questions are asked only if HEAT permits analysis of these variables for the zone prototype. Zones that are typically the largest are designed to permit analysis of these variables. Exhibit 6 gives the zone prototypes and configuration options for HVAC system, percentage area used, and window orientation that are available for each zone.

\section{Zone Prototype Zone Description}

Configuration Option HVAC Area Windows Type- Used Face

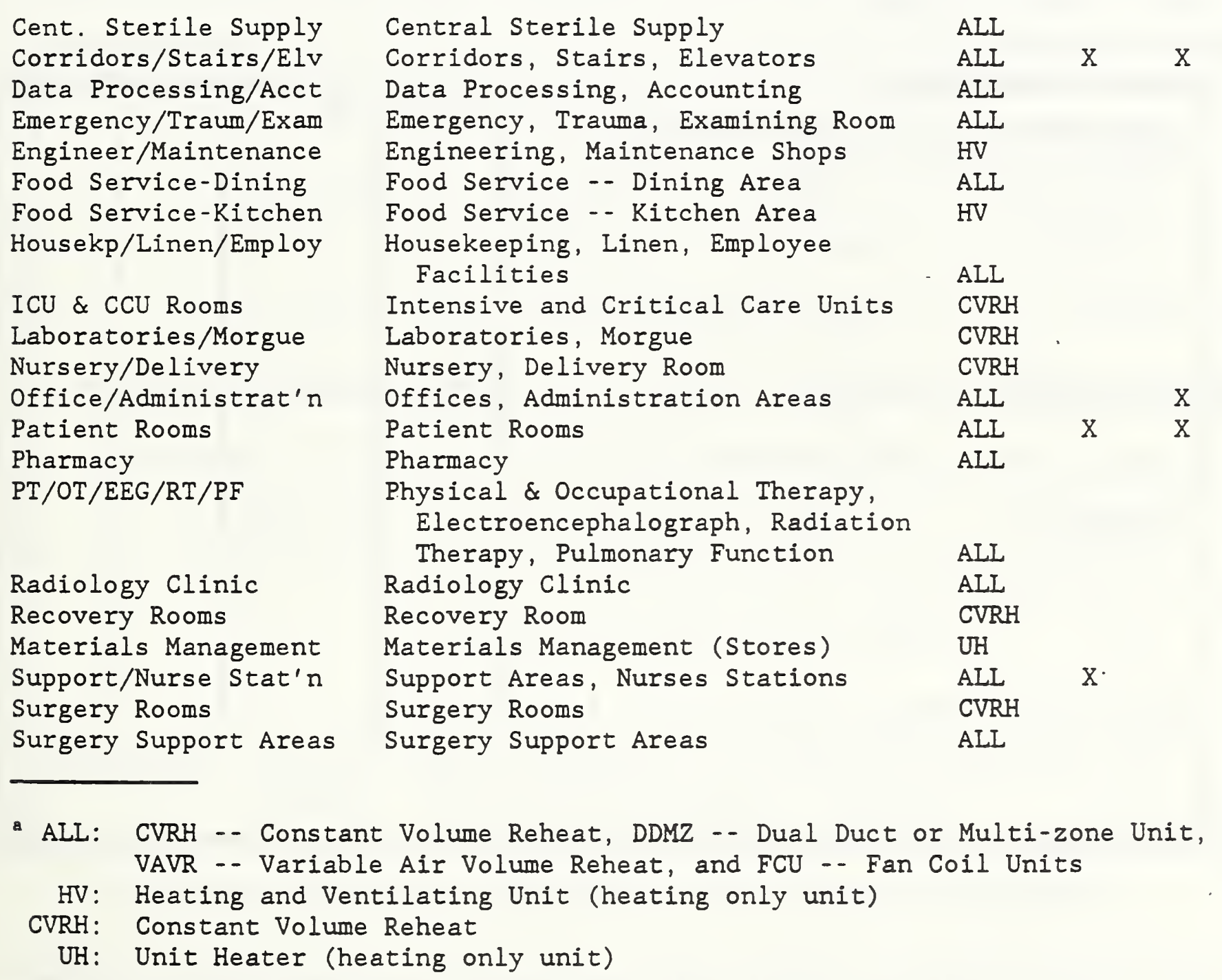

Exhibit 6. Zone Prototypes and Available Configuration Options 
While defining zones, press F5 to edit any of the entries and Del to delete any zone entirely. Once all zones are defined, you may either Benchmark your energy use or enter and analyze Energy Saving Plans by zone. To Benchmark, press Esc for the HEAT menu and then select Energy Use Benchmark (see next section). To analyze a zone, move the cursor to highlight it and press F6.

Now enter data describing the Energy Saving Plan you would like to analyze for that zone (Exhibit 7). For each zone, you will be offered up to 10 Energy Saving Methods [ESMs] to select. The particular ESMs available for a zone depend on engineering judgment regarding their appropriateness for the zone. For example, zones that are typically situated in interior space are not offered the two window-related ESMs. For Lighting Hours enter the number of hours per week you plan to reduce lighting time. Enter the Status Now and Planned for the other ESMs available for the zone. The Status values are set initially to the most likely values for each zone, and your entries are limited to ranges reasonable for each zone and ESM. HEAT cannot estimate energy usage for values outside these reasonable ranges.

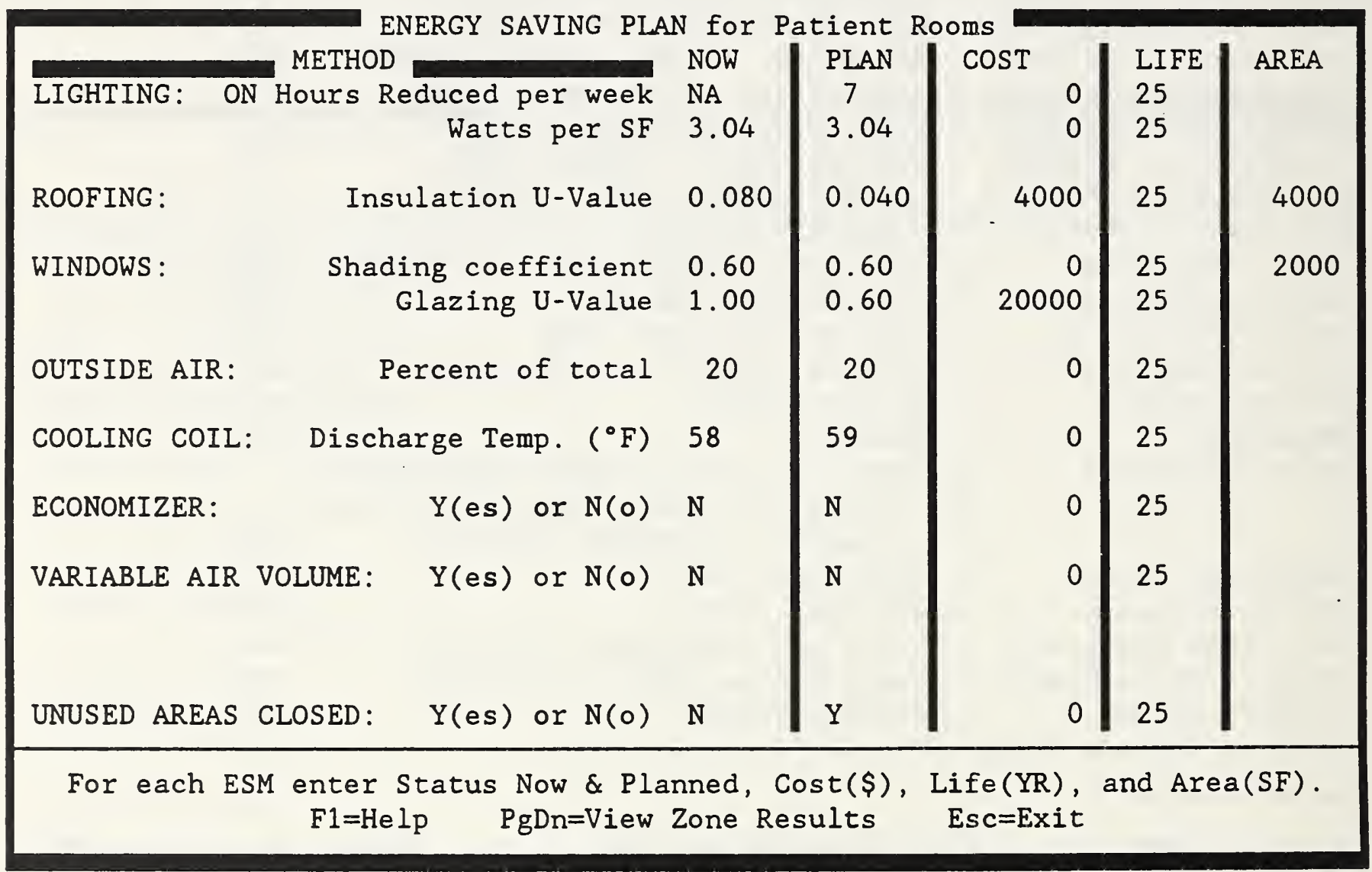

Exhibit 7. Entering Energy Saving Plan for Patient Rooms Zone

Enter the expected Cost, if any, of installing or initiating each ESM. If the ESM must be replaced one or more times before the end of the Study Period, change the life to reflect the time between replacements. The replacement cost is assumed to be the same as the current initial cost in constant dollars. For 
example, if the Life is 10 years and the Study Period is 30 years, the Cost will be incurred three times (once now, and at the end of years 10 and 20). The Cost, Life, Study Period, and Real Discount Rate are used to compute the Present Value Cost of the ESM. If the ESM is expected to last through or beyond the Study Period, replacement is unnecessary so leave the life equal to the Study Period.

For roof and window ESMs, enter the Area in square feet to be treated. The Roof Area may not exceed the floor area of the zone, and the Window Area may not exceed twice the floor area of the zone.

To exclude an ESM, enter the same (i.e., its current) value for both Status Now and Planned and leave the Cost at zero and the Life equal to the Study Period.

When the Energy Saving Plan is complete, press PgDn to estimate the energy savings and display the economic results for that zone (Exhibit 8).

\section{ENERGY AND ECONOMIC ANALYSES for Patient Rooms}

ANNUAL ENERGY SAVINGS BY ENERGY FUNCTION:

$\begin{array}{cccc}\begin{array}{c}\text { Heating } \\ \begin{array}{c}\text { Distillate } \\ \text { gal }\end{array}\end{array} & \begin{array}{c}\text { Cooling } \\ \text { Electric } \\ \mathrm{kWh}\end{array} & \begin{array}{c}\text { Other } \\ \text { Electric } \\ \mathrm{kWh}\end{array} & \begin{array}{c}\text { TOTAL ENERGY } \\ \text { All Fuels } \\ \text { MBtu }\end{array} \\ 5,586 & 52,699 & 28,046 & 1,050\end{array}$

ECONOMIC ANALYSIS

PRESENT VALUE SAVINGS OVER 25 YEARS BY ENERGY FUNCTION:

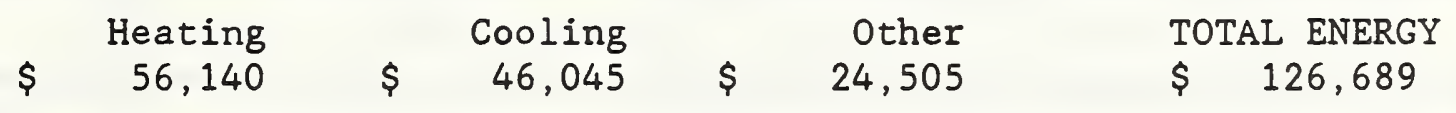

PRESENT VALUE COSTS OVER 25 YEARS: $\$ 24,000$

NET PRESENT VALUE SAVINGS OVER 25 YEARS: \$ 102,689

Press

Exhibit 8. Energy and Economic Results for Patient Rooms Zone

The top half of this screen reports the estimated energy savings per year due to the combination of ESMs selected. Energy savings are reported separately for heating, cooling, and other electricity (e.g., lights, fans, pumps, and plug-in equipment). The savings for these three functions are also summed to report 
total annual energy savings in million Btu's. The bottom half of the screen reports the dollar savings over the Study Period attributed to these recurring energy savings, taking into account the fuel prices, discount rate, and system efficiencies. Also reported is the present value cost over the Study Period, which is the discounted sum of investment and replacement costs for all the ESMs. Finally, the difference between time-adjusted savings and costs, or net present value, is displayed. Press $\longleftarrow$ to return to the ZONE DESCRIPTIONS screen, now with present value savings and costs reported for Patient Rooms (Exhibit 9).

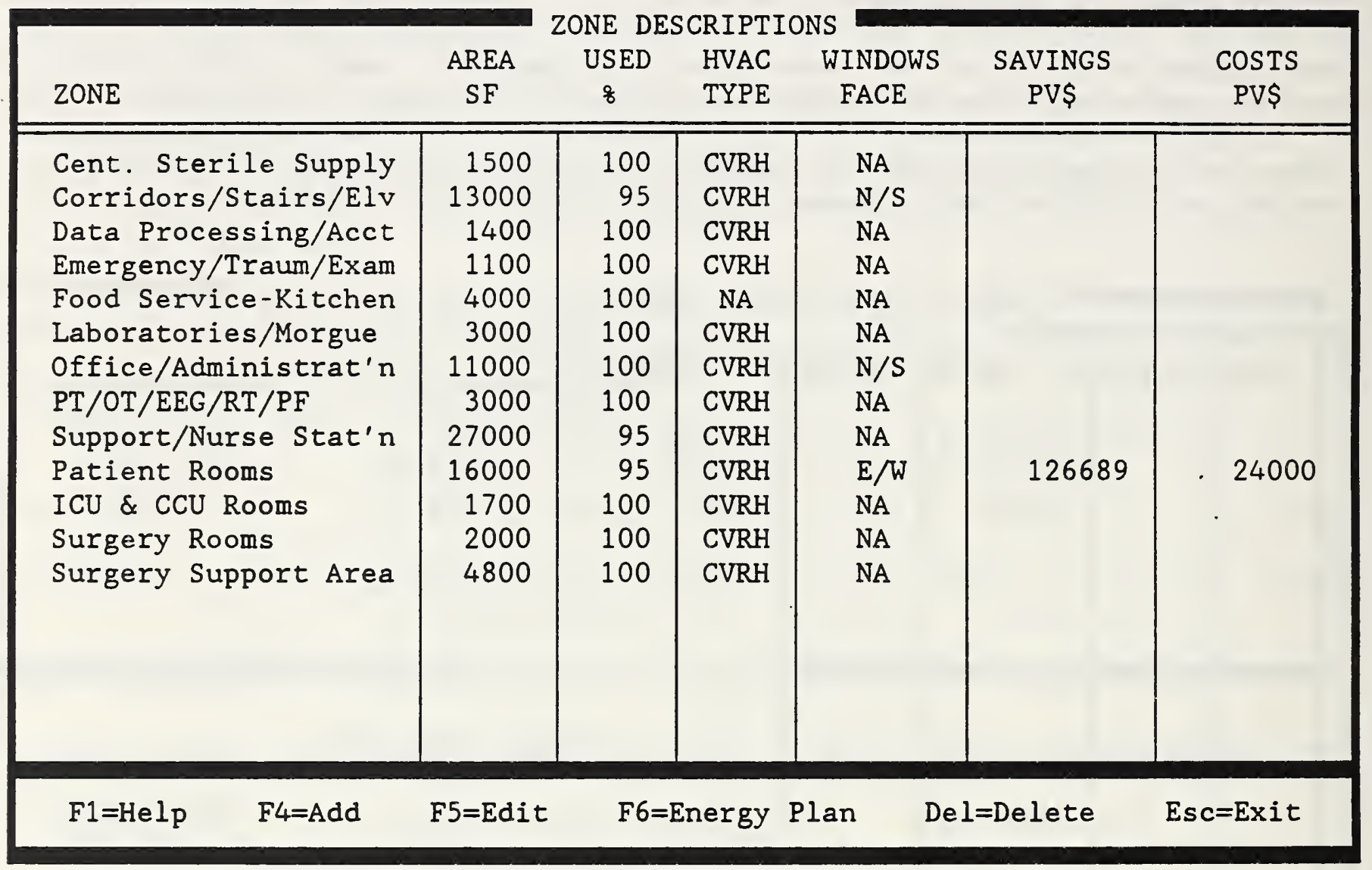

\section{Exhibit 9. ZONE DESCRIPTIONS with Patient Room Energy Plan Results}

You may want to analyze multiple Energy Saving Plans for each zone to compare energy savings and economic results. Keep in mind, however, that only the latest versions of your Hospital Data and Energy Saving Plans are saved by HEAT, so print data and results as you go by holding down the Shift key and pressing the PrintScrn key.

You may even change assumptions you made in the Hospital Data module to see the effect on results. After making changes to Hospital Data, however, be sure to update the energy and economic results stored in the file by pressing F6 from the ZONE DESCRIPTIONS table (Exhibit 5) and then pressing PgDn at the zone's ENERGY SAVING PLAN screen (Exhibit 7). Repeat this procedure for every hospital zone defined. 


\section{ENERGY USE BENCHMARK}

From the HEAT menu select the module Energy Use Benchmark. A worksheet appears that may be used to check whether the current energy use of your hospital is in line with national averages for hospitals like yours. You simply fill in the monthly purchases of each type of fuel you use. The Benchmark is meaningful only after all hospital zones are defined, since it is based on the total floor area of all defined zones. Make sure that the total floor area matches the actual hospital area heated and cooled by the fuel consumption recorded.

After filling in your fuel consumption press F10 to display the totals and compare your consumption with a national Benchmark (Exhibit 10). Your fuel consumption is used to compute your hospital's actual Energy Use Index (EUI), measured in 1000 BTU per square foot per year. This Actual EUI is then compared with an estimate of a Normal (national average) EUI for a hospital with the same zones and same zone floor areas as yours. The percentage difference of the Actual to the Normal is displayed.

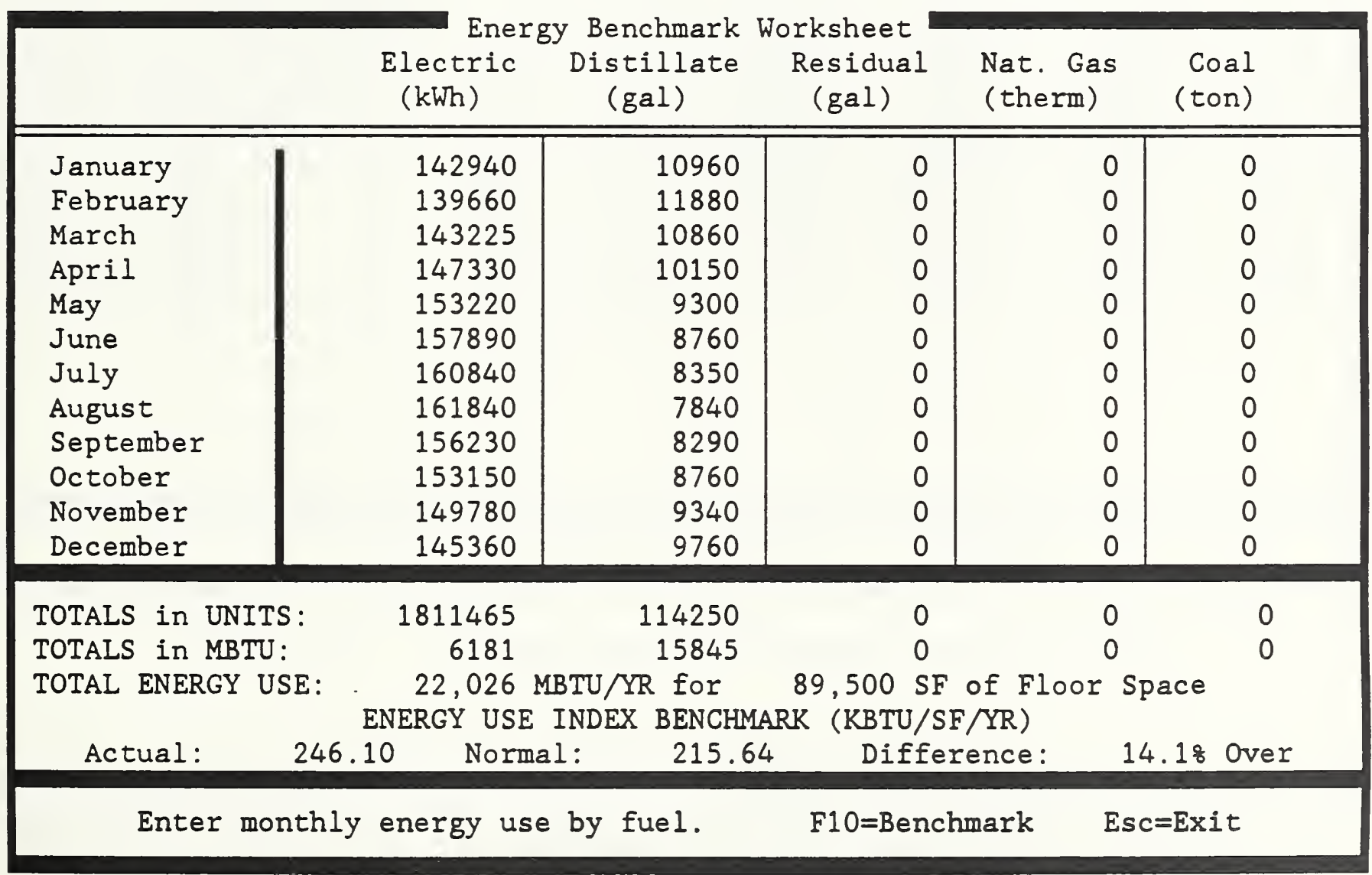

Exhibit 10. Benchmarking Your Hospital's Energy Use 
These benchmarking results suggest how significant the energy saving opportunities are likely to be in your hospital. Be aware, however, that even if your hospital uses less energy than the national average, some ESMs may still be cost effective, especially if fuel prices are relatively high in your area. 


\section{RESULTS}

This module displays in a single table the energy and economic results of the Energy Saving Plans for every zone (Exhibit 11). The annual savings of energy used for Heating, Cooling, and Other Electricity are separately displayed. The economic results are displayed as the Present Values of all energy savings and of all Costs, discounted over the Study Period. The Net Present Value representing the difference between savings and costs is also shown in the far right column of the table.

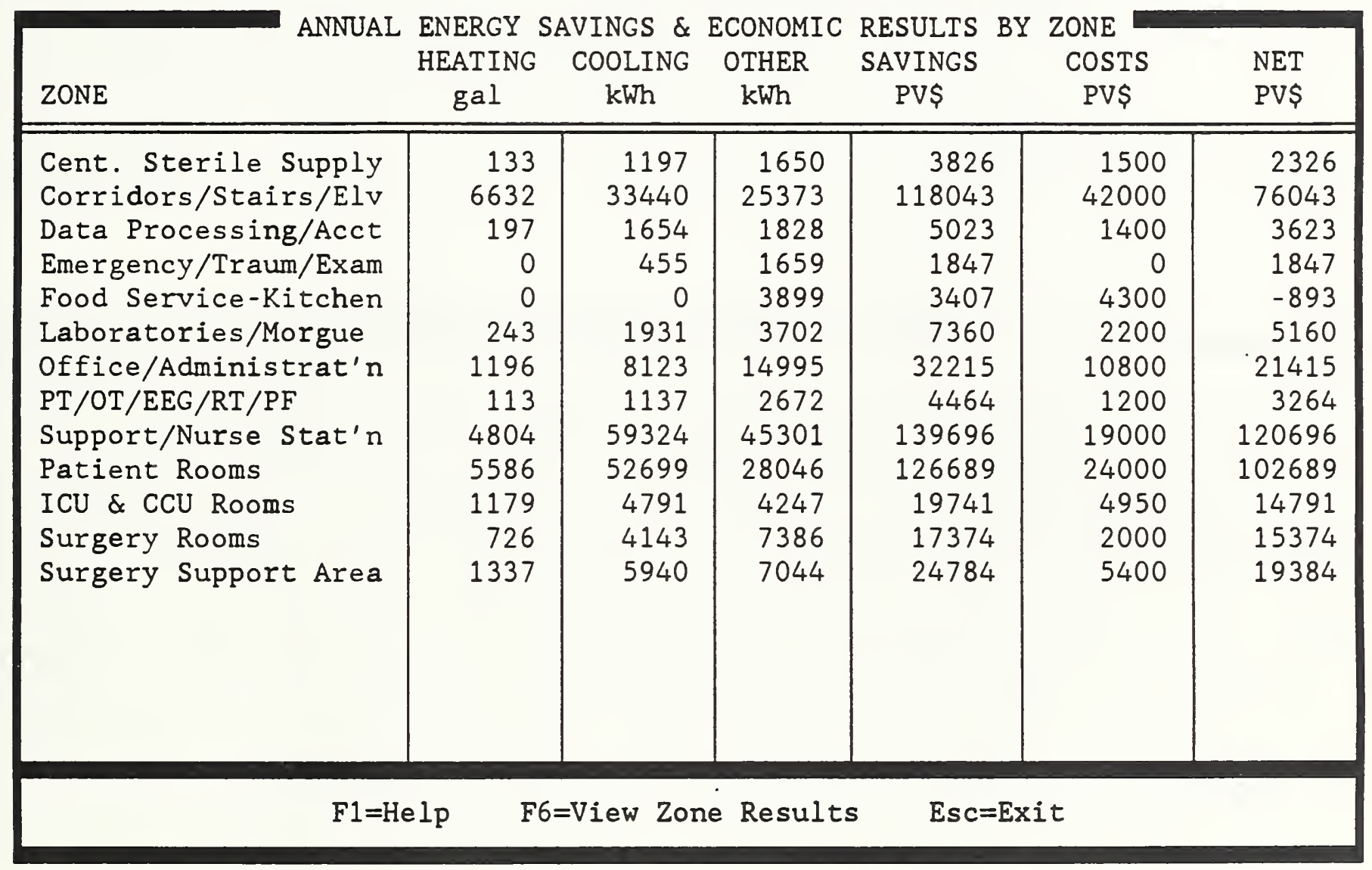

Exhibit 11. Viewing Energy and Economic Results by Zone

To view the detailed energy and economic analysis results of any zone, use $\uparrow$ and $\downarrow$ to highlight the zone and then press F6. If any of the Hospital-wide data have been changed since the zone's Energy Saving Plan was developed, the energy and economic results must be updated before the results are correctly displayed in this Results module. For example, suppose you change one of your fuel prices. To update the results, return to the ZONE DESCRIPTIONS table (Exhibit 5) and press F6 and then press PgDn at the zone's Energy Saving Plan screen (Exhibit 7). This procedure must be followed for every zone defined. 
HEAT evaluates the cost effectiveness of specific Energy Saving Methods (ESMs) applied to a user-defined hospital environment. The Benchmarking feature of HEAT shows whether the current energy use of your hospital is in line with national averages for hospitals of similar configuration and size. The benchmarking results suggest how significant the energy saving opportunities are likely to be in your hospital.

HEAT may be used initially with "best guess" estimates of ESM cost to evaluate alternative Energy Saving Plans and identify the most promising ESMs for which bids should be sought. Once bids have been received, rerun HEAT using actual ESM bid prices to better estimate cost effectiveness. For ESMs requiring a large capital investment, a qualified engineer should confirm the energy savings estimated by HEAT, based on a more comprehensive analysis of your hospital. 


\begin{tabular}{|l|r|l|}
\hline $\begin{array}{l}\text { NIST-114A } \\
\text { (REV. 3-89) }\end{array}$ & U.S. DEPARTMENT OF COMMERCE \\
& NATIONAL INSTITUTE OF STANDARDS AND TECHNOLOGY & $\begin{array}{l}\text { 1. PUBLCATION OR REPORT NUMBER } \\
\text { NISTIR 4408 }\end{array}$ \\
\cline { 3 - 4 } & BIBLIOGRAPHIC DATA SHEET & $\begin{array}{l}\text { PERFORMIMG ORGANIZATION REPORT NUMBER } \\
\text { 3. PUBLCATION DATE } \\
\text { SEPTEMBER } 1990\end{array}$ \\
\hline
\end{tabular}

4. TITLE AND SUBTITLE

Hospital Energy Analysis Toolkit [HEAT]: User Manual

5. AUTHOR(S)

Stephen F. Weber and Barbara C. Lippiatt

6. PERFORMING ORGANIZATION (IF JOINT OR OTHER THAN NIST, SEE INSTRUCTIONS) U.S. DEPARTMENT OF COMMERCE NATIONAL INSTITUTE OF STANDARDS AND TECHNOLOGY GAITHERSBURG, MD 20899

9. SPONSORING ORGANIZATION NAME AND COMPLETE ADDRESS (STREET, CITY, STATE, ZIP)

U.S. Department of Health and Human Services

Public Health Service, Office of Health Facilities

5600 Fishers Lane

Rockville, MD 20857

10. SUPPLEMENTARY NOTES

DOCUMENT DESCRIBES A COMPUTER PROGRAM; SF-185, FIPS SOFTWARE SUMMARY, IS ATTACHED.

11. ABSTRACT (A 200-WORD OR LESS FACTUAL SUMMARY OF MOST SIGNIFICANT INFORMATION. IF DOCUMENT INCLUDES A SIGNIFICANT BIBLOGRAPHY OR UTERATURE SURVEY, MENTION IT HERE.)

The Hospital Energy Analysis Toolkit [HEAT] is a menu-driven microcumputer software program designed to help facility managers of existing hospitals evaluate the cost effectiveness of specific Energy Saving Methods (ESMs). The program estimates the energy savings and cost effectiveness of specific ESMs in a user-defined hospital environment. Hospitals are defined in terms of an unlimited number of actual functional space zones, each modeled after one of 21 prototype zones. For each defined zone, the user specifies the floor area, and for some zones the user specifies the types of heating and cooling systems, the percentage of space being actively used, and the window orientation. The user also defines an Energy Saving Plan by specifying the current and planned status of each energy parameter applicable to the particular zone. HEAT then computes and reports the energy and economic savings resulting from the Plan. A benchmarking function lets users compare current energy use of the entire hospital with national norms to see whether further analysis is warranted. HEAT offers easy-to-use menus and function keys, on-line help screens, and data validation.

12. KEY WORDS (6 TO 12 ENTRIES; ALPHABETICAL ORDER; CAPITALIE ONLY PROPER NAMES; AND SEPARATE KEY WORDS BY SEMICOLONS) cost effectiveness; decision support software; economic evaluation; energy conservation; hospitals; life-cycle cost analysis; microcomputer software

13. AVAILABILITY

\section{$\mathrm{X}$ UNLIMITED}

FOR OFFICIAL DISTRIBUTION. DO NOT RELEASE TO NATIONAL TECHNICAL INFORMATION SERVICE (NTIS).

ORDER FROM SUPERINTENDENT OF DOCUMENTS, U.S. GOVERNMENT PRINTING OFFICE, WASHINGTON, DC 20402.

ORDER FROM NATIONAL TECHNICAL INFORMATION SERVICE (NTIS), SPRIMGFIELD, VA 22161.
14. NUMBER OF PRINTED PAGES

$$
22
$$

15. PRICE

$\mathrm{AO} 2$. 


